\title{
A polifonia de enunciadores nas cartas dos leitores: uma abordagem enunciativa
}

\author{
The polyphony enunciators in letters from readers: a stated approach \\ Telma Cristina Gomes da Silva \\ Universidade Federal de Campina Grande - Campina Grande - Paraíba - Brasil
}

$\diamond$

\begin{abstract}
Resumo: Este trabalho analisa o gênero discursivo carta do leitor à luz da Teoria da Argumentação na Língua desenvolvida por Anscombre, Ducrot $(1977,1987,1988)$ e colaboradores para quem a língua e seus usos são fundamentalmente argumentativos. A análise incide sobre uma amostragem constituída por 03 cartas dos leitores recortadas de um corpus mais amplos coletado nas revistas Istoé e Veja entre janeiro e março de 2003. Nesse corpus, identificamos as marcas linguístico-discursivas ativadoras de pressuposto, considerando o dialogismo entre o locutor e os outros enunciadores (vozes sociais) para a constituição da carta. Os resultados apontaram que a negação polêmica constitui um recurso linguístico produtor de sentido na carta do leitor, mostrando a polifonia de enunciadores como uma das principais estratégias argumentativas nesse gênero discursivo.
\end{abstract}

Palavras-chave: Argumentação; Gênero discursivo; Polifonia de enunciadores

\begin{abstract}
This paper analyzes the discursive genre reader's letter to the Theory of Argumentation in language developed by Anscombre, Ducrot $(1977,1987,1988)$ and colleagues for whom language and its uses are fundamentally argumentative. The analysis focuses on a sample consisting of 03 letters from readers cut out of a larger corpus collected in magazines and Istoé and Veja between January and March 2003. In this corpus, we identify the linguistic-discursive marks activating assumption considering the dialogism between speaker and other enunciators (social voices) for the establishment of the letter. The results showed that the controversy denial is a linguistic resource producer of meaning in the reader's letter, showing the polyphony enunciators as a major argumentative strategies in this discursive genre.
\end{abstract}

Keywords: Argumentation; Discursive genre; Polyphony enunciators

\section{Introdução}

Este estudo a respeito da polifonia de enunciadores no gênero carta do leitor pressupõe a noção de texto bakhtiniana. A partir dessa concepção, o texto é o dado primário para investigar a linguagem em uso, uma vez que, a palavra e/ou signo representa e materializa os pontos de vista dos locutores do discurso. Diante disso, analisamos a carta do leitor, tendo como hipótese que o fenômeno discursivo da polifonia de enunciadores - aquela que consiste na relação que o locutor estabelece com os enunciadores em seu texto e/ou discurso - constitui sua principal estratégia argumentativa.

Na carta do leitor, observamos as marcas linguísticodiscursivas que caracterizam a presença de outros discursos no discurso do locutor desse gênero discursivo, sendo a linguagem compreendida como lugar de interação entre dois sujeitos, o "eu" e o "outro", e o gênero como "tipos relativamente estáveis de enunciados" (BAKHTIN, 2000, p. 279).

A análise está fundamentada na Teoria da Argumentação na Língua, desenvolvida por Anscombre, Ducrot $(1977,1987,1988)$ e colaboradores, cuja tese norteadora - reescrita por Espíndola, 2004 - é que a língua e seus usos são fundamentalmente argumentativos. Nessa teoria, encontramos o conceito de polifonia - a idéia de que o enunciado constitui um diálogo entre vozes, isto é, cada palavra expressa à relação que um sujeito estabelece com outro sujeito (DUCROT, 1987; DUCROT, 1988) - que oferece subsídios para entender à construção de sentidos do texto numa perspectiva enunciativa. 
Ressalta que essa ideia de polifonia origina-se com os estudos de Bakhtin e o Círculo para quem o dialogismo constitui o princípio constitutivo da linguagem e a condição essencial para o sentido do texto. Por essa visão, todo e qualquer texto resulta da interação entre diferentes sujeitos, pois, esses sujeitos, o mundo e os próprios textos se constituem, culturalmente, através da contraposição, da contrapalavra, da interação entre pontos de vista, crenças e juízos de valor.

A escolha da carta do leitor entre as outras variantes de carta se deve a esse gênero permitir ao leitor comum $^{1}$ participar das discussões públicas de igual para igual com outros sujeitos socais, tendo em vista que as cartas são veiculadas em portais nacionais e internacional. Logo, esse gênero oferece a seu locutor um poder de voz mais amplo em relação aos temas abordados nas revistas em que coletamos os dados de pesquisa. Assim, entendemos ser relevante compreender o funcionamento semântico-argumentativo desse gênero.

\section{O gênero discursivo carta do leitor}

É preciso retomar, brevemente, neste trabalho, o conceito bakhtiniano de gênero discursivo. Bakhtin (2000) define os gêneros discursivos como formas enunciativas, orais ou escritas, estáveis, históricas e socialmente situadas. De acordo com esse estudioso,

Todas as esferas da atividade humana, por mais variadas que sejam, estão sempre relacionadas com a utilização da língua. [...] $\mathrm{O}$ enunciado reflete as condições específicas e as finalidades de cada uma dessas esferas, não só por seu conteúdo (temático) e por seu estilo verbal, ou seja, pela seleção operada nos recursos da língua [...], mas também, e sobretudo, por sua construção composicional. [Isto significa que] cada esfera de utilização da língua elabora seus tipos relativamente estáveis de enunciados, sendo isso que denominamos gêneros do discurso (grifos do autor) (BAKHTIN, 2000, p. 279).

Partindo disso, Bakhtin (2000), em sua teoria, preocupou-se em distinguir os gêneros do discurso em primários e secundários. Segundo ele, os gêneros denominados de primários (simples) são as formas discursivas que se constituem em circunstâncias de uma comunicação espontânea (réplica de diálogo, narrativa de costumes, cartas etc.), enquanto que os gêneros chamados de secundários (complexos) são aqueles que "aparecem

\footnotetext{
Chamamos leitor comum a pessoa física, não-institucional que escreve para revistas, a fim de dar seu ponto de vista nas discussões de caráter público como também reivindicar ações do poder público entre outras coisas.
}

em circunstâncias de uma comunicação cultural, mais complexa e relativamente mais evoluída, principalmente na escrita: artística, científica, sociopolítica" (BAKHTIN, 2000, p. 281).

Essa distinção entre os gêneros primário e secundário é de relevante valor teórico, uma vez que:

A inter-relação entre os gêneros primários e secundários de um lado, o processo histórico de formação dos gêneros secundários do outro, eis o que esclarece a natureza do enunciado (e, acima de tudo, o difícil problema da correlação entre língua, ideologias e visões do mundo) (BAKHTIN, 2000, p. 282).

A partir dessa noção, a carta é um gênero do discurso simples, originado nas/para as comunicações do cotidiano sendo alterada e/ou modificada quando absorvida por um gênero do discurso complexo, como por exemplo, o romance. Paredes Silva (1997) estuda mais, especificamente, o gênero carta. Segundo ela, a carta é um texto funcional utilizado "em situações de ausência de contato imediato entre emissor e destinatário. No entanto, a categoria carta, 'tout court', é muito ampla, não dando conta da diversidade de textos e de propósitos nela encontrados" (PAREDES SILVA, 1997, p. 121).

Essa estudiosa acrescenta que a estrutura composicional da carta:
permite qualquer tipo de comunicação: desde as vantagens de um determinado cartão até informações sobre o condomínio, passando pelas esperadas noticias do amigo que mora no exterior. Todas são cartas, mas não devemos colocá-las na mesma categoria. (PAREDES SILVA, 1997, p. 121, grifos da autora)

Consideramos, então, a carta um gênero complexo devido a suas variantes remeterem para diferentes campos da atividade humana, como confirma a estudiosa citada:

\begin{abstract}
A carta é sem dúvida um gênero. [...] Trata-se, porém, de um gênero complexo. Dentro dela, não há correspondência preferencial a alguma estrutura discursiva (do tipo procedural-receita): ela pode apresentar todos os tipos básicos de estruturas, o que se constata pelo conjunto de traços lingüísticos já mencionados (tempo, aspecto, modo, pessoa focalizada, etc) (PAREDES SILVA, 1997, p. 123).
\end{abstract}

Essa visão corroborar com este estudo, pois, a carta é vista como gênero discursivo complexo constituído por diversas variantes com funções sociais diferenciadas, ao contrário do postulado por Bakhtin (2000) em sua teoria. Para ele, 
em sua grande maioria, os gêneros literários são gêneros secundários, complexos, que são compostos de diversos gêneros primários [simples] transformados (réplicas de diálogo, narrativas de costumes, cartas, diários íntimos, documentação, etc). (BAKHTIN, 2000, p. 325).

Essa problemática dos gêneros está relacionada à diversidade de critérios que podem ser utilizados de forma legítima para definir um gênero, provocando uma enorme polêmica entre os estudiosos da linguagem. Nesse aspecto, deixamos claro que adotaremos a perspectiva de Bakhtin como suporte teórico para a nossa investigação por ser o gênero concebido como um enunciado, entretanto, nossa concepção de carta, enquanto gênero discursivo, é que essa é um gênero complexo, por ser constituída por diversas outras variantes de cartas com características especificas, como postulado por Paredes Silva (1997).

Em suma, a estrutura discursiva do gênero "cartas"2 não corporifica um tipo específico, dividindo-se em subgêneros ou variantes, como por exemplo, carta programa, carta de apresentação, carta reposta, carta de solicitação, carta pessoal, carta ao leitor, carta do leitor, dentre outras. Por exemplo, essa última variante incorpora algumas vezes a estrutura discursiva de outros gêneros como o artigo de opinião, ou ainda, a correspondência eletrônica (e-mail), dificultando sua caracterização. Pois, a carta possui uma estrutura organizacional que permite qualquer tipo de comunicação adequando-se ao contexto em que está inserida.

De acordo com Melo (1999), as cartas recebidas pela redação de jornais (e/ou revistas) passam por uma triagem ou seleção antes de públicas, com exceção de alguns casos previstos por lei como o direito de resposta. A seleção ocorre porque, assim como o leitor tem um interesse em particular de comentar determinado fato ou acontecimento etc., o editor deve zelar pelo interesse do público leitor e do próprio veículo. Feita a seleção, as cartas ainda passam pela edição, isto é, por uma reformulação e/ou modificação do texto original para adequar-se ao espaço reservado no veículo.

No caso deste trabalho, a carta do leitor está inserida no suporte revista, no qual os jornalistas reduzem o

\footnotetext{
2 Ressaltamos que o gênero "cartas" apresenta uma superposição de propósitos havendo algum que se pode destacar como predominante (cf. DIONÍSIO, 2002, p. 21). Diante disso, alguns autores dizem que o foco da carta está na comunicação em si, no contato do locutor com seu interlocutor, e não no conteúdo que essa leva aos leitores. Desse modo, o recorte da carta não seria prejudicial, já que o foco está no contato. Entretanto, quando falamos da carta do leitor o conteúdo tem um papel bastante significativo, ultrapassando a simples comunicação entre locutor e interlocutor. Isto porque, diferente das outras variantes de carta - apresentação, solicitação, programa, pessoal -, a carta do leitor é um instrumento de opinião, que possibilita ao leitor participar ativamente de debate sobre questões públicas.
}

conteúdo da carta, dentre outras coisas, por questões de espaço, destacando a reportagem à qual a carta faz referência, mas também visando direcionar a leitura do texto. Deduzimos, então, que esse recorte pela edição pode provocar um novo direcionamento argumentativo no texto, pois há um corte do conteúdo, e consequentemente, no sentido do texto. Ademais, as cartas são introduzidas ao público através de títulos que também direcionam a leitura. Com isso, podemos afirmar que há uma manipulação dos conteúdos publicados nas CLs pelas revistas e jornais.

Diante dessas considerações, caracterizamos a carta do leitor como um gênero que circula no contexto jornalístico, em seção fixa de revistas e de jornais denominados comumente de cartas, cartas à redação, carta do leitor, painel do leitor, reservada à correspondência dos leitores (MELO, 1999), sendo esse gênero usado com diversos propósitos comunicativos - criticar, elogiar, opinar, reivindicar, esclarecer etc. A partir disso, esse gênero discursivo é considerado como pertencente ao domínio público, tendo entre seus objetivos a divulgação de temáticas das revistas e dos jornais (impresso ou virtual).

Logo, a carta do leitor, em sua essência, é uma forma desses meios de comunicação fazerem propaganda de suas matérias, pois em muitos dos casos os leitores elogiam o trabalho realizado por esses veículos. Como podemos observar nos recortes, a seguir:

CL.I.13 (05/03/2003) - "Parabéns pela excelente reportagem [...] Mais uma vez, um grande trabalho de denúncia de crime $[. .]$.$" .$

CL.I. 14 (05/03/2003) - "A reportagem sobre as confissões de ACM é sem dúvida, pelo conteúdo, uma das melhores que ISTOÉ nos brindou este ano [...]".

CL.I.17 (12/03/2003) - "Na edição 1742, a matéria 'Impressões digitais' sobre os grampos telefônicos, muito bem elaborada pelos autores, [...]".

Isso significa que a carta do leitor "transmite uma idéia de veracidade pelo fato de o texto não ser uma criação de uma empresa de publicidade, mas uma opinião sincera de um cliente" (SOUTO MAIOR, 2001, p. 08). Analisamos, então, a carta do leitor observando as marcas linguístico-discursivas responsáveis pela orientação argumentativa. Para tal leitura, recuperamos alguns textos aos quais a carta faz referência, visto que a compreensão da carta depende não somente do que nela está posto, mas também de fatores pragmáticos como: conhecimento linguístico, conhecimento de mundo, conhecimento partilhado, etc.

Desse modo, a compreensão dos possíveis efeitos de sentido produzidos pela/na carta do leitor faz necessário que identifiquemos: 
1. os textos com os quais a carta dialoga, no caso, as reportagens às quais essas cartas fazem referência ou as personagens e fatos por elas trazidos;

2. o contexto sócio-histórico e as circunstâncias em que os fatos ocorreram, isto é, o momento da enunciação;

3. as intenções dos locutores das cartas, considerando a relação que esses sujeitos estabelecem com os pontos de vistas que trazem em suas cartas; e

4. os elementos linguísticos essenciais para uma análise semântico-argumentativa do texto.

\section{A Argumentação na Língua: da antiguidade as teorias do discurso}

O domínio da palavra é considerado por muitos um dom, porém vários estudiosos da antiguidade postulam que a oratória, a interação verbal, o convencer, o persuadir, o conquistar através do verbo, do discurso é uma arte, e, portanto, uma técnica que pode ser desenvolvida com estudo. É desta arte - a argumentação - que trataremos nesta seção.

$\mathrm{Na}$ Antiguidade, a argumentação era ensinada pela retórica, "a antiga arte de persuadir e de convencer" (PERELMAN, 1999, p. 15), como uma técnica do discurso persuasivo e estava diretamente associada à política. Essa técnica do discurso persuasivo foi reduzida à ornamentação da linguagem pela retórica clássica torna-se o estudo das figuras de estilo dos textos poéticos, isso fez o discurso persuasivo desaparecesse do espaço intelectual ${ }^{3}$.

Essa perspectiva persistiu até o século XX, quando Roland Barthes busca em Aristóteles os princípios que regem o raciocínio lógico e, por sua vez, a leitura de Barthes influencia o filósofo Chaïm Perelman que elaborou uma Nova Retórica. Para Perelman (1999), a argumentação consiste em buscar persuadir um auditório, sendo a relação entre o locutor e seu público constitutiva da enunciação, sendo, portanto, o ato de argumentar a maneira como o locutor age sobre seu alocutário, modificando suas convicções e suas disposições através do discurso mediado pela interação verbal.

Considerando essa visão, Ducrot $(1987,1988)$ trabalha a orientação argumentativa dos enunciados dentro da linha da Semântica da Enunciação. Para Ducrot (1987, p. 168), a argumentação é um "acontecimento constituído pelo aparecimento de um enunciado. A realização de um enunciado é de fato um acontecimento histórico". Com esse pensamento, o referido estudioso procura compreender a construção da relação de sentidos, rompendo com a unicidade do sujeito nos enunciados.

Dessa visão surge a chamada Teoria da Argumentação na Língua - postulada por Anscombre e
Ducrot - na década de 1970 com trabalhos sobre a pressuposição. Esses estudiosos partem do princípio de que a argumentatividade está inscrita na própria língua, sendo essa essencialmente argumentativa.

\section{Polifonia: as marcas da enunciação para/na argumentação}

Koch (1987, p. 145) afirma que "a polifonia é um fato constante no discurso, que oferece ao locutor a possibilidade de tirar consequências de uma asserção cuja responsabilidade não assume diretamente, atribuindo-a a um enunciador estranho".

Para Bakhtin (2002, p. XII, grifos do autor), a polifonia é "o discurso do diálogo inacabado, [ou seja], não é possivel dizer tudo sobre uma época por mais que dela se saiba", sendo o discurso constituído nas relações dialógicas sob as condições da comunicação, isto é, com a palavra em seu uso concreto.

Ducrot (1987) incorporou esse conceito de polifonia bakhtiniano à pragmática linguística empregando-o aos enunciados - pequenos segmentos do discurso ${ }^{4}$ - com a finalidade de contestar a unicidade do sujeito falante, ou seja, a ideia de que um enunciado possui somente um único auto; alegando que em um mesmo enunciado simples há um diálogo entre vozes, isto é, o locutor nunca se expressa, diretamente, mas coloca em cena, no mesmo enunciado, outros personagens. Nessa visão, o sentido do enunciado e não só do texto como um todo - é construído a partir do confronto entre diferentes vozes e/ou sujeitos.

Partindo disso, Ducrot distingue os diferentes tipos de sujeitos da enunciação, caracterizando-os de acordo com suas funções sociais em: sujeito empírico (SE), locutor (L) e enunciador (E). Segundo ele, não se pode atribuir a um único sujeito os atributos de:

a) ser dotado de toda atividade psico-fisiológica necessária à produção do enunciado: b) ser autor, a origem dos atos ilocutórios realizados na produção do enunciado (atos do tipo da ordem, da pergunta, da asserção etc); c) e ser designado em um enunciado pelas marcas da primeira pessoa (DUCROT, 1987, p. 178-179).

Dessa distinção surge o conceito de polifonia de enunciadores. Sendo essa entendida como a relação que

\footnotetext{
O desaparecimento da antiga retórica é tratado em "O Império Retórico" de Perelman (1999).

4 Salientamos que a concepção de enunciado de Ducrot (1988) compreende a frase em sua realização - a língua em uso - diferente da perspectiva bakhtiniana, na qual o enunciado é concebido não como frase, mas como toda e qualquer forma de discurso e/ou texto. Para esse estudioso, a língua é um conjunto de frases e/ou enunciados encadeados que constituem o discurso, enquanto que, para Bakhtin (2000), a língua é o próprio discurso.
} 
o locutor estabelece com as vozes e/ou enunciadores apresentados em seu discurso. Para Ducrot (1987), esse tipo de polifonia está relacionado com a encenação teatral dos personagens (enunciadores) no enunciado. Ressalta-se que, segundo esse estudioso, o par enunciador/ locutor corresponde ao par personagem/autor da teoria bakhtiniana, pois o locutor, assim como o autor, dá existência a personagens (enunciadores) de quem organiza os pontos de vista e as atitudes.

Ademais, a polifonia de enunciadores é mais ampla que a polifonia de locutores (dois sujeitos que se opõem ou dialogam), pois, permite explicar uma série de fenômenos discursivos que indicam a presença de outras vozes em um mesmo enunciado, afirma Koch (2000). Entre esses fenômenos estão: a negação, o humor, o uso dos operadores argumentativos, a pressuposição, o discurso indireto livre dentre outros. Mas, neste trabalho, analisaremos apenas o recurso linguístico negação.

\section{A negação polifônica}

Ducrot (1988) afirma que o enunciado negativo apresenta dois pontos de vista opostos atribuídos, respectivamente, a um enunciador $\mathbf{E} 1$ e outro enunciador E2, em outras palavras ${ }^{5}$,

\begin{abstract}
en un enunciado negativo no-P, hay por lo menos dos enunciadores: um primer enunciador E1 que expresa el punto de vista representado por $\mathrm{P}$, y um segundo enunciador E2 que presenta um rechazo de esse punto de vista. Un enunciado negativo es pues una especie de diálogo entre dos enunciadores que se opnem el uno al outro (DUCROT, 1988, p. 23).
\end{abstract}

Observemos um exemplo com encadeamentos introduzidos por expressões linguísticas do tipo pelo contrário: (1) João não é um amigo leal; pelo contrário, tem-se demonstrado pouco confível. Pelo primeiro segmento do enunciado (não-P) João não é um amigo leal, podemos distinguir dois pontos de vista: um positivo segundo o qual João é um amigo leal e outro que rechaça o anterior. Enquanto que no segundo segmento introduzido por pelo contrário não se opõe a João não é um amigo leal e sim à asserção de $\mathbf{L}=\mathbf{E} 1$ (João é um amigo leal). Isso significa que no segundo segmento do enunciado se faz ouvir outra voz implícita na afirmação de E1 para a qual o operador pelo contrário se dirige.

Para análise dos enunciados negativos, Ducrot (1987, p. 203-204) distingue três formas de negação:

\footnotetext{
"uma declaração negativa não-P, há pelo menos dois enunciadores: um enunciador primeiro E1 expressando o ponto de vista representado por P, e segundo enunciador E2 que rejeita esse da vista. A declaração negativa é, portanto, uma espécie de diálogo entre dois enunciadores que se opõem" (DUCROT, 1988, p. 23, tradução nossa).
}

1. Metalingüística - esta negação contradiz os próprios termos de uma fala efetiva à qual se opõe, permitindo anular os pressupostos do positivo subjacente, exemplo, (1) 'João não deixou de beber, ele nunca bebeu'. Este 'não deixou de beber', que não pressupõe bebia antes, só é admitido como resposta a um locutor que tenha dito 'João deixou de beber'. Dito de outro modo, a negação metalingüística 'contesta um locutor que enunciou seu positivo correspondente' (ESPÍNDOLA, 2004, p. 75). Nesse caso, a negação tem efeito de explicitar e anular os pressupostos.

2. A Polêmica é o segundo tipo de negação. Nesta o locutor identifica-se ao enunciador $\mathbf{E 2}$ da recusa, opondo-se não a um locutor, mas a um enunciador E1. Ao contrário da metalingüística, essa forma de negação tem sempre um efeito rebaixador e mantém os pressupostos. Um exemplo, (2) 'Diogo não é trabalhador; de fato, ele nunca trabalhou na vida' (E1 = Diogo é trabalhador). Ou seja, o L de (2), assimilando-se ao enunciador (E2) opõe-se ao enunciador (E1), que veicula o ponto de vista: Diogo é trabalhador.

3. O terceiro tipo de negação é a Descrição - essa é diferente das anteriores, pois não tem por objetivo contrapor um enunciado, mas apenas descrever algo.Vejamos um exemplo, (3) 'Diogo não é orgulhoso', se posso descrever Diogo dizendo 'ele não é orgulhoso', estou atribuindo-lhe uma característica que se opõe a um enunciador que tenha afirmado que 'ele é orgulhoso'.

Salientamos que a distinção entre a negação descritiva e a negação metalingüística foi estabelecida por Ducrot (1977), objetivando sustentar que o recurso da negação pode manter os pressupostos de uma proposição P. Segundo o referido estudioso, "para declarar que uma determinada negação é, por exemplo, metalingüística é justamente porque ela põe em jogo elementos que deveríamos considerar como pressupostos" (DUCROT, 1977, p. 114), enquanto que a negação descritiva descreve fatos explicitados no texto.

Apresentada a noção de negação da Teoria da Enunciação de Ducrot, bem como considerando os fatores, até então colocados, fez-se necessário antes de identificarmos os elementos linguístico-discursivos responsáveis pela orientação argumentativa nos textos, recuperarmos as matérias com as quais eles dialogam explicitamente. Isto é, observamos se há um diálogo explícito com as reportagens às quais as cartas respondem polifonicamente.

Essas reportagens estão relacionadas ao episódio dos "grampos telefônicos" no Congresso durante o período da 
eleição presidencial em 2002. Além desses textos, outras informações estão implícitas nas cartas constituindo vozes a exemplo de fatos históricos e conhecimento de mundo, etc. Outro aspecto observado diz respeito às intenções do locutor da carta ao trazer para seu enunciado outras vozes responsáveis pela construção de sentido, isto é, qual a relação que o locutor estabeleceu com os pontos de vista veiculados em seu texto. No caso, deste artigo, o uso da negação.

Segundo Ducrot (1987, p. 142-143), um enunciado negativo:

apresenta sua enunciação como a realização de dois atos, respectivamente, a asserção [...], e a recusa da asserção. Ora, é claro que estes dois atos não são atribuídos ao mesmo ser. É verdade que a recusa é atribuída ao locutor [...], mas asserção recusada é atribuída a alguém que pode ser o alocutário, um terceiro determinado, ou a voz pública.

Nesse tipo de enunciado, o locutor (L) se assimila ao enunciador (E2) da recusa desaprovando o ponto de vista colocado por (E1). Para a análise, adotamos também outros dois conceitos: informação compartilhada - é a informação já citada no texto origem da carta (matéria da revista), ou ainda, já citada na própria carta - e informação nova - é a informação que não citada na matéria origem, nem, antecipadamente, na carta, ou ainda, as informações veiculadas pelo locutor como supostamente compartilhadas entre ele e seu interlocutor. Em suma, "o locutor veicula um conteúdo como se fosse uma informação compartilhada, mesmo sabendo que é uma informação nova" (SILVA, 2004, p. 55), dirigindo-a ao interlocutor de maneira que esse aceite, sem contestar, seu discurso e/ou ponto de vista.

\section{Análise: a negação como um recurso argumentativo da/na carta do leitor}

O discurso do locutor é materializado na/pela carta do leitor, a partir de um já dito, sendo, assim, um posicionamento do sujeito "eu" em relação à voz de "outro" sujeito e/ou discurso. Desse ângulo, o discurso resulta da relação dialógica estabelecida entre o "eu" e o "outro", como afirmam Bakhtin e o Círculo, e por sua vez, a construção de sentidos na/da carta do leitor é fundamentada pela (re)corrência de já ditos (informações compartilhadas ou supostamente compartilhadas) e/ou enunciados negativos que caracterizam a argumentatividade presente no texto, como poderemos observar nas cartas 01,02 e 03 analisadas a seguir:

\section{Carta 01:}

\section{CLI.06.(26/02/2003)}

ACM não consegue aprender nada de positivo depois de tantas tragédias ocorridas em sua vida. Não se envolver em assuntos escabrosos é impossível para este velho político, cujo estilo já deveria ter sido exterminado do cenário brasileiro. O governo federal deve exigir uma criteriosa investigação e daí a criação de uma CPI para que possamos ver, mais uma vez, este senador sair desmoralizado pela porta dos fundos.

(1a) posto. O governo federal deve exigir uma criteriosa investigação e daí a criação de uma CPI para que possamos ver, mais uma vez, este senador sair desmoralizado pela porta dos fundos.

(1b) pressuposto. ACM em momento anterior já saiu desmoralizado pela porta dos fundos do Congresso.

A carta 01 traz a proposição, $\boldsymbol{A C M}$ não consegue aprender nada de positivo depois de tragédias ocorridas em sua vida, que é atribuída a um enunciador (E2), a quem o locutor (L) se assimila. Esse desaprova o ponto de vista colocado por (E1), representado pela proposição, ACM aprendeu com as tragédias ocorridas em sua vida. Assim, o L da carta 01 coloca em cena, no mesmo enunciado, dois pontos de vista opostos: (E1), apresentado uma perspectiva positiva sobre $\mathrm{ACM}$ e (E2), opondo-se à perspectiva colocada por (E1), a quem o L se identifica. Essa primeira proposição é atribuída a um interlocutor virtual colocado em cena pelo L, para ser rechaçado. Ou seja, o L imagina um diálogo com um interlocutor virtual para expressar o próprio ponto de vista.

Ainda na carta 01 , verificamos outra sentença negativa, Não se envolver em assuntos escabrosos é impossível para este velho político, na qual distinguimos um enunciador (E1) responsável pela proposição (P), $\boldsymbol{E}$ impossível ACM se envolver em assuntos escabrosos, rechaçado pelo $L$ do texto, que se assimila ao enunciador (E2) da refutação de (E1). Logo o L traz um ponto de vista atribuído a um interlocutor virtual para rechaçá-lo, visto que a asserção atribuída a (E1) não está expressa na matéria origem do texto. Desse modo, o L utiliza a negação como uma tática argumentativa que lhe permite colocar seu ponto de vista como uma resposta a um suposto interlocutor. A utilização dessa estratégia vem confirmar o que diz Bakhtin (2002): o "eu" se constitui no diálogo que estabelece com o "outro", fazendo do discurso, um discurso bivocal.

Além disso, analisando a sentença, $O$ governo federal deve exigir uma criteriosa investigação e daí a criação de uma CPI para que possamos ver, mais uma vez, este senador sair desmoralizado pela porta dos fundos, colocado como posto pelo L, podemos inferir o pressuposto (1b), ACM em momento anterior já saiu 
desmoralizado pela porta dos fundos do Congresso, introduzido pela expressão lingüística mais uma vez. Este pressuposto remete para um momento anterior à enunciação da carta 01 , contido no dito ( $1 b$ ), e apresentado como uma informação compartilhada entre locutor e interlocutor do texto, já que vem explicitada no conteúdo da matéria veiculada pela revista.

\section{Carta 02:}

\section{CLI.13.(05/03/2003)}

Parabéns pela excelente reportagem. Entretanto, temo que tudo acabe em acarajé. ACM não desistiu da C.C.J. por medo ou para preservar o Senado, mais sim por ter garantido junto ao "inimigo de ontem, o PT" um acordo, livrando-o de uma possível CPI. Mais uma vez, um grande trabalho de denúncia de crime e absolutamente ninguém é efetivamente punido.

(2a) posto. Mais uma vez, um grande trabalho de denúncia de crime.

(2b) pressuposto. Anteriormente, já houve grandes trabalhos de denúncia de crimes no Brasil

Na carta 02 , temos a proposição, $\boldsymbol{A C M}$ não desistiu da C.C.J. por medo ou para preservar o Senado, mais sim por ter garantido junto ao "inimigo de ontem, o PT" um acordo, livrando-o de uma possível CPI, na qual distinguimos dois enunciadores: o primeiro enunciador (E1), responsável pelo ponto de vista representado por (P), ACM desistiu da C.C.J. por medo ou para preservar o Senado, reprovado pelo locutor (L), que se assimila ao enunciador (E2), responsável pelo enunciado (não-P). Explicitando melhor, o L traz para seu enunciado o ponto de vista de (E1) para rechaçá-lo, identificando-se com a perspectiva colocada pelo (E2), o enunciador da recusa. $\mathrm{O}$ ponto de vista representado por (E1) é atribuído a um interlocutor imaginário trazido para o discurso pelo L, com a finalidade de refutá-lo prevalecendo a fala de (E2), a quem o L se assimila.

Ademais, na carta 01, temos outra proposição, Mais uma vez, um grande trabalho de denúncia de crime, na qual distinguimos: em um primeiro nível, o conteúdo posto (2a), atribuído ao L do texto; e, em um segundo nível, o conteúdo pressuposto (2b), Anteriormente, já houve grandes trabalhos de denúncia de crimes no Brasil, ativado pela expressão linguística mais uma vez. Embora, se assimile ao (E2), o L, ao veicular como pressuposto o ponto de vista de (E1), compartilha com seu interlocutor a informação implícitada na segunda proposição da carta 02. Ressalta-se que, através do pressuposto (2b), o L veicula uma informação compartilhada que remete para as matérias, anteriormente, veiculadas pela ISTOÉ, e, portanto, faz parte do conhecimento prévio dos participantes da interação.

\section{Carta 03:}

CLV.24.(26/02/2003)

$\mathrm{O}$ senador $\mathrm{ACM}$ não se emenda, mesmo.O septuagenário que se diz "paladino" da moralidade e por isso deveria dar bons exemplos à família, notadamente aos filhos e netos, é mais uma vez o protagonista não somente de atos ilícitos, mas também de um escandaloso "triângulo amoroso"!

(3a) posto. O septuagenário que se diz "paladino" da moralidade [...], é mais uma vez o protagonista não somente de atos ilícitos, mas também de um escandaloso "triângulo amoroso".

(3b) pressuposto. Anteriormente, ACM também foi protagonista de atos ilícitos.

Na carta 03, recortamos a proposição, $O$ senador ACM não se emenda, mesmo, na qual verificamos a negação como ativadora de polifonia. Nesse exemplo, o locutor (L) coloca em cena, através do enunciador (E1), um ponto de vista representado por (P), O senador $\boldsymbol{A C M}$ se emenda; $\mathrm{e}$, por meio do enunciador (E2), ele desaprova esse ponto de vista. Ou seja, (E1) e (E2) põem em cena perspectivas diferentes, e o L assimilará a perspectiva introduzida por (E2). Essa estratégia argumentativa é utilizada por L como uma forma de resposta a um interlocutor (revista), a quem aquele se opõe. Confirmando que o "eu" se constitui em confronto com o "outro", e, por sua vez, o dialogismo é constitutivo da língua(gem).

$\mathrm{Na}$ proposição, O septuagenário que se diz "paladino" da moralidade [...], é mais uma vez o protagonista não somente de atos ilícitos, mas também de um escandaloso "triângulo amoroso", a expressão linguística mais uma vez ativa o pressuposto (3b), Anteriormente, ACM também foi protagonista de atos ilícitos. Polifonicamente, o pressuposto ( $3 b$ ) é atribuído a um enunciador (E1), responsável pelo conteúdo implicitado em nessa proposição; entretanto, o L se assimila ao enunciador (E2), o responsável pelo conteúdo posto (3a). Esse pressuposto se constitui como uma informação compartilhada colocada explicitamente na matéria da revista.

\section{Considerações finais}

A análise de enunciados introduzidos pela partícula negativa não, mostrou que o locutor (L) da carta do leitor coloca em cena um ponto de vista atribuído a um enunciador (E1), para rechaçá-lo, assimilando-se ao enunciador (E2), o responsável pelo ponto de vista discordante.

Observamos que a negação, pelo menos, na carta do leitor, é utilizada pelo L para dialoga com um interlocutor real ou virtual, a quem L rechaça, algumas vezes, com 
a finalidade de aprovar o ponto de vista expresso pela revista. Logo, a estratégia da negação utilizada pelo L, não se constitui, sempre, como uma forma de desaprovação ao (E1) presente na matéria origem do texto, mas também a um enunciador (E1) virtual, a quem o L direciona uma resposta para expressão seu ponto de vista.

Salientamos que a forma de negação analisada no discurso das cartas dos leitores foi a negação denominada por Ducrot (1987) de polêmica. Nesse tipo de negação, o (E2) utiliza um enunciado (não-P) para replicar a afirmação colocada em cena por (E1). Ou seja, (E1) e (E2) põem em cena pontos de vista opostos, e o L irá se identificar ao enunciador (E2), da refutação.

Constatamos que o recurso investigado, negação polêmica, foi pertinente, neste estudo, pois o uso desse recurso funciona como um índice ativador de polifonia nas cartas dos leitores. Pois, nos enunciados introduzidos por ela, o L coloca em confronto seu ponto de vista com um ponto de vista atribuído a um interlocutor real ou virtual, representado por (E1). Esse enunciador é rechaçado por $\mathrm{L}$ para predominar seu ponto de vista na carta.

Diante disso, a análise comprova nossa hipótese básica de que a polifonia de enunciadores constitui a principal estratégia argumentativa da carta do leitor, sendo essa responsável pela orientação pretendida pelo locutor para construir sentidos para o seu texto. Logo, o uso da negação como ativador de polifonia nas cartas dos leitores confirma também a tese postulada por Ducrot e Anscombre (reescrita por Espíndola, 2004) de que a língua e seus usos são fundamentalmente argumentativos.

\section{Referências}

BAKHTIN, M. Estética da criação verbal. 2. ed. São Paulo: Martins Fontes, 2000.

BAKHTIN, M. Problemas da poética de Dostoiévski. Tradução por Paulo Bezerra. Rio de Janeiro: Ed. Forense-Universitária, 2002.
CUNHA, L. C.; DINIZ, W. Espionagem: Grampo que vem da Bahia. Revista ISTOÉ, São Paulo, n. 1741, p. 29-33, 12 fev. 2003.

CUNHA, L. C.; DINIZ, W. Congresso: Impressões Digitais. Revista ISTOÉ, São Paulo, n. 1743, p. 24-28, 26 fev. 2003.

CUNHA, L. C.; DINIZ, W. Política: Confissões de ACM. Revista ISTOÉ, São Paulo, n. 1742, p. 29-33, 12 fev. 2003.

CUNHA, L. C.; DINIZ, W. Congresso: Grampo com Recibo. Revista ISTOÉ, São Paulo, n. 1745, p. 38-41, 12 mar. 2003.

CUNHA, L. C.; DINIZ, W. Política: Grampos em Família. Revista ISTOÉ, São Paulo, n. 1746, p. 30-31, 19 mar. 2003.

DUCROT, O. Princípios de Semântica Lingüística (dizer e não dizer). São Paulo: Cultrix, 1977. p. 11-148; p. 232-234.

DUCROT, O. O dizer e o dito. Campinas, SP: Pontes, 1987.

DUCROT, O. Polifonia y argumentacion. Universidade del Valle-Cali, 1988.

ESPÍNDOLA, L. C. A Entrevista: um olhar argumentativo. João Pessoa: EDUFPB, 2004.

KOCH, I. G. V. Desvendando os segredos do texto. São Paulo: Cortez, 2002.

MELO, C. T. V. Cartas à redação: uma abordagem discursiva. Tese de Doutorado, UNICAMP, 1999.

PARENTES SILVA, V. L. Variações tipológicas no gênero textual carta. In: KOCH, I. G. V.; BARROS, K. S. M. de (orgs.). Tópicos em lingüística de texto e análise da conversação. Natal: EDUFRN, 1997. p. 118-124.

PERELMAN, C. O império retórico: retórica e argumentação. 2. ed. Lisboa: Asa Editores, 1999.

SILVA, J. M.; ESPÍNDOLA, L. (orgs.). Argumentação na língua: da pressuposição aos Topoi. João Pessoa: Editora Universitária/UFPB, 2004.

SOUTO MAIOR, A. C. O gênero carta - Variedade, uso e estrutura. In: Ao pé da letra. UFPE, v. 3, p. 1-13, 2001.

Recebido: 18 de agosto de 2015.

Aprovado: 28 de novembro de 2015.

Contato: telmapedist@hotmail.com 